\title{
Relationship between maturity levels and neuromuscular capacity among youth soccer players and individuals not practicing soccer
}

\author{
Dihogo Gama de Matos ${ }^{1^{*}}$, Estélio Henrique Martin Dantas ${ }^{2}$, Felipe José Aidar ${ }^{1,3,4}$, \\ Aldo Coelho Silva ${ }^{5}$, Bernardo Minelli Rodrigues ${ }^{2}$, Ingi Klain ${ }^{1}$, Robert C. Hickner ${ }^{6}$, \\ André Luiz Carneiro ${ }^{1,7}$, Mauro Lucio Mazini Filho ${ }^{1}$

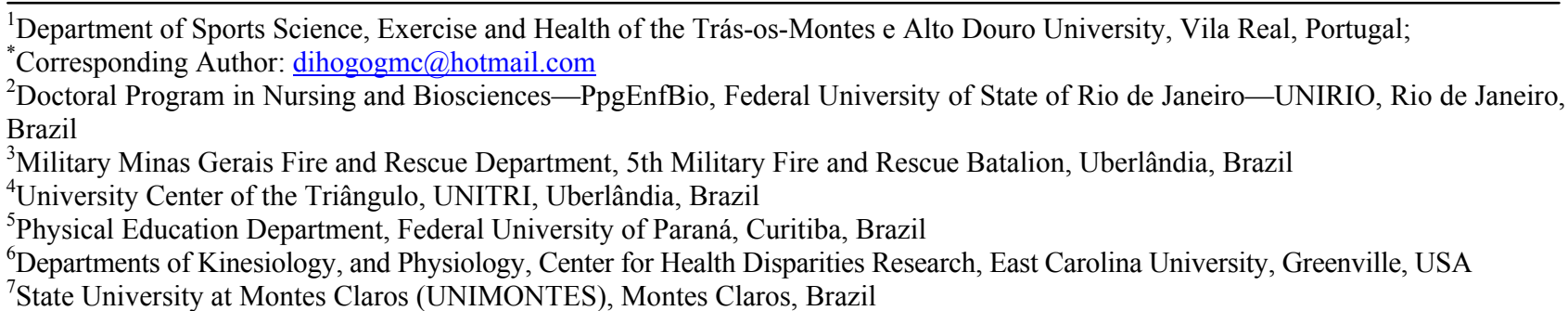

Received 19 October 2012; revised 21 November 2012; accepted 3 December 2012

\section{ABSTRACT}

The aim of this study was to compare maturational stage and neuromuscular skills among soccer players and non-athletes, as well as to investigate the relationship between maturation and neuromuscular performance. Twenty five adolescent males (14.3 \pm 0.45 years) participated in the study and were divided into two groups: soccer players $(\mathrm{SP}-\mathrm{n}=13,14.1 \pm 0.3$ years, 58.9 $\pm 6.90 \mathrm{~kg}, 1.72 \pm 0.04 \mathrm{~m}, 19.9 \pm 1.7 \mathrm{~kg} \cdot \mathrm{m}^{2}, 13.3 \% \pm$ $4.3 \%$ fat) and non-athletes (NA - n = 12, $14.5 \pm$ 0.5 years, $57.3 \pm 6.9 \mathrm{~kg}, 1,67 \pm 0.06 \mathrm{~m}, 20.6 \pm 3.9$ $\mathrm{kg} \cdot \mathrm{m}^{2}, 14.0 \% \pm 5.7 \%$ fat). The square test and 20 $\mathrm{m}$ speed test were used to assess agility and speed, respectively. The Tanner self-assessment of pubic hair and genitalia development test was used to estimate maturational development. The Shapiro Wilk test was used to verify the normality of samples. For any data not normally distributed, the non-parametric Mann Whitney test, as well as Kendall's Tau correlation test, were used. The $p$-values determined for agility $(p=0.017)$ and speed $(p=0.054)$ indicated that agility was the only variable significantly different between SP and NA. The SP and NA groups showed no difference in the levels of maturation $(p=0.41)$, and maturational status was not significantly correlated with agility $(r=0.013)$ or speed $(r=$ -0.003 ). Conclusion: Individuals who practiced football had better results for the agility test than non-athletes, even with no difference between the degree of maturation and speed. There is a low correlation between level of maturity and agility or speed.

Keywords: Training; Maturity; Physical Capabilities

\section{INTRODUCTION}

Soccer is the most practiced sport in Brazil and has a large following throughout the world. In all age groups there are people playing soccer, with distinct goals in each age-group. In Brazil, soccer initiation occurs in early childhood, often with the encouragement of their parents or on the initiative of the child as a result of sport idols [1]. This sport is characterized by high intensity efforts, interspersed with moments of low intensity. The main physical attributes involved in a game of soccer are aerobic endurance, speed, agility, power, flexibility and strength/endurance [2]. Speed and agility are considered determinants of performance, as soccer is characterized by sprinting, quick changes of direction and turns, which are considered crucial because these actions are decisive for the game [3-5].

Soccer training promotes adaptations in participants. When comparing variables between practitioners and those not playing soccer, soccer players tend to have better soccer-related performance that appear to be due to differences between the groups in body morphology and motor performance $[1,6]$. Maturation can alter the performance, and this influence is taken into account when 
interpreting physical tests [7]. In football, high levels of maturity may promote changes in young players and can promote better performance [8].

Analyzing the effects of training on soccer players, there are studies that show no difference between those practicing and not practicing soccer in relation to body composition and some motor performances, such as velocity and agility $[1,6,9,10]$. Additionally, in relation to maturity, there are studies that show no difference in the maturity levels, performance capacity and body morphology in younger soccer players $[10,11]$.

Some studies have analyzed the differences between soccer athletes and non athletes at different levels of maturation $[10,11]$. Non-athletes were included to analyze whether the sporting experience and/or biological maturation was a predictor of athletic performance.

The objective of this study was therefore to compare the maturity levels and neuromuscular capabilities among soccer players and those not playing soccer, and to determine the relationship between maturity and neuromuscular capabilities. The findings would allow determination of whether soccer playing experience and/or biological maturation is a better predictor of athletic performance.

\section{PROCEDURES}

The sample consisted of 25 adolescent males age 14.3 \pm 0.4 years divided into two groups: SP (soccer practitioners: $\mathrm{n}=14,14.1 \pm 0.3$ years, $58.9 \pm 6.90 \mathrm{~kg}, 1.72 \pm$ $0.04 \mathrm{~m}, 19.9 \pm 1.7 \mathrm{~kg} \cdot \mathrm{m}^{2}$ and $13.3 \% \pm 4.3 \%$ fat $)$ and NA (non-athletes: $\mathrm{n}=11,14.5 \pm 0.5$ years, $57.3 \pm 6.9 \mathrm{~kg}, 1.67$ $\pm 0.06 \mathrm{~m}, 20.6 \pm 3.9 \mathrm{~kg} \cdot \mathrm{m}^{2}$ and $14.0 \% \pm 5.7 \%$ fat). The volunteers were informed about the study and signed the authorization according to resolution 196/1996 of the National Health Council, in accordance with the ethical principles contained in the Declaration of Helsinki (1964, revised in 1975, 1983, 1989, 1996 and 2000), and the World Medical Association. The procedures were approved by the institution ethics committee. This research was approved by the Ethics Committee in Research of Severino Sombra University-USS, Vassouras, RJ-Brazil under number CAAE-0131.0.326.000-10.

The SP activities were performed for a minimum of six months three times a week comprising an hour and thirty minutes of practice per day of training. The training consisted of physical conditioning, technique and tactics outside of Physical Education classes. The NA had no systematic practice of any sport, but did participate in Physical Education classes, which took place once a week for an hour and a half and consisted of cooperative games according to the school's annual plan. For inclusion, the participants were male adolescents between 14 and 15 years of age who did not participate in organized sport or physical activity other than during physical education classes, or during soccer for SP. The exclusion criteria included those volunteers who had musculoskeletal injury or used of medication that could interfere with performance in the study.

\section{PROCEDURES}

Three separate test periods were conducted. The first test session was held to familiarize the participants with the explanation and application of speed and agility tests and the self-assessment of maturity. At the second meeting, anthropometric measurements (body mass and height) were made, followed by the self-assessment of maturity, and finally, tests of agility and speed. On the third session only the tests of agility and speed were conducted.

To assess body mass, stature, body mass index (BMI) and percentage body fat, a digital mechanical scale (Filizola, Brazil) for body mass in kilograms $(\mathrm{kg})$ with a precision of $0.1 \mathrm{~kg}$, a Sanny stadiometer (Sanny, Brazil) for stature (m) with an accuracy set at $0.1 \mathrm{~cm}$, and a skinfold calipers (Cescorf, Scientific Cescorf Brazil) to determine body composition were utilized. Subsequent calculations were made for body mass index (BMI) according to the description of Mascarenhas et al., [12] and for body fat percentage using the protocol of Lohman [13].

For the analysis of the maturational development, selfassessment of secondary sexual characteristics was performed as proposed by Tanner [14] where levels of maturation are divided from one to five: one being the level seen pre pubertal and 5 being post pubertal and considered to be full maturity. Self assessment of maturational stage was determined by comparison with drawings indicating the five levels of maturation.

The tests conducted in this study were tests of speed and agility as follows: 1) $20 \mathrm{~m}$ Speed Test performed on a 20 meter track [15]. Three parallel lines were marked on the ground as follows: the first (starting line), the second line, $20 \mathrm{~m}$ far from the first line (timing) and the third line, marked at one meter from second (finish line). The third line is a reference for the participant that was used in an attempt to prevent the participant from slowing down before crossing the finish (timing) line 2) Square test of agility [16]. A square was drawn on the ground with four feet of distance between the four cones $(50 \mathrm{~cm}$ tall cones). The participant started from a standing position, with one foot advanced forward immediately behind the starting line. At the sign of the tester, the participant moved to the next cone in his left diagonal. Subsequently, they ran toward the cone to their right and then moved to the cone diagonally (diagonally across the square). Finally, they ran toward the last cone, which was the starting point. The participant touched with one hand each of the cones that marked out the route. The timer was triggered by the assessor at the time the participant performed the first step with the foot touching the inside 
of the square and was stopped when the participant passed the last cone. During testing, all evaluated received a verbal stimulus from the evaluators to do the best time possible on all attempts.

Before each test of agility and speed, there was a fiveminute warm up for the main muscle groups used in the tests. Two minutes after the end of the warm up, the first test of agility was conducted. After thirty minutes from the end of the agility test, the speed test occurred. The student had three attempts at each test, with an interval of three minutes between each attempt, with the fastest time used for the performance time.

\section{STATISTICS}

All data was checked for assumptions of normality using descriptive statistics and the Shapiro Wilk test. If the distribution was determined to be non-parametric, the Mann Whitney test was used to verify the difference between the test groups. The Kendall Tau correlation was used to determine correlations between maturation and performance measures in the speed and the agility tests. The level of significance was set a priori at $\mathrm{p}<$ 0.05. All data analysis was performed using SPSS for Windows version 15.0.

\section{RESULTS}

Table 1 presents descriptive anthropometric data for the two groups. No significant differences were found for any of the anthropometric variables except for stature ( $p$ $<0.01)$.

Table 2 represents the mean values for the tests of agility and speed of the SP and NA groups. A significant difference was found in agility with the SP scoring higher than the NA group $(\mathrm{p}<0.03)$.

Table 3 shows that there was no significant difference between SP and NA $(p=0.41)$ in regard to the estimation of sexual maturation.

Table 4 shows the correlations between the level of maturation and physical characteristics (body mass, height, BMI and percent fat) and physical performance $(20 \mathrm{~m}$ test and square test). There were no significant correlations. Correlations were performed on all study subjects, forming a single group.

\section{DISCUSSION}

Many studies have reported physiological changes that occur with athletic training in youth $[1,6,17]$. However, the magnitude and speed with which changes occur need to be further researched. The specificity of soccer training promotes improvements in performance in its practitioners, although maturation may play a role in this improvement.
Table 1. Characterization of the participants.

\begin{tabular}{ccc}
\hline & SP & NA \\
\hline Age (years) & $14.1 \pm 0.3$ & $14.5 \pm 0.5$ \\
Body mass $(\mathrm{kg})$ & $58.9 \pm 6.9$ & $57.3 \pm 6.9$ \\
Stature $(\mathrm{m})$ & $1.72 \pm 0.04$ & $1.67 \pm 0.06^{*}$ \\
BMI $\left(\mathrm{kg} / \mathrm{m}^{2}\right)$ & $19.9 \pm 1.7$ & $20.6 \pm 3.9$ \\
$\%$ fat & $13.3 \pm 4.3$ & $14.0 \pm 5.7$ \\
\hline
\end{tabular}

$\mathrm{SP}=$ soccer practitioners; NA $=$ non-athletes; ${ }^{*}$ Significantly different from SP group $(\mathrm{p}<0.001)$.

Table 2. Tests of speed and agility for each group.

\begin{tabular}{cccc}
\hline & SP (seconds) & NA (seconds) & P \\
\hline Speed & $3.15 \pm 0.20$ & $3.35 \pm 0.30$ & 0.05 \\
Agility & $5.07 \pm 0.25$ & $5.22 \pm 0.35$ & $0.017^{*}$ \\
\hline
\end{tabular}

$\mathrm{SP}=$ Group soccer practitioners; $\mathrm{NA}=$ non-athletes; ${ }^{*}=$ significant difference between groups.

Table 3. Distribution of the maturational development of the participants.

\begin{tabular}{ccc}
\hline & $\mathrm{SP}(\mathrm{n}=14 \%-100 \%)$ & $\mathrm{NA}(\mathrm{n}=11 \%-100 \%)$ \\
\hline Stage I & $-/-$ & $-/$ \\
Stage II & $-/-$ & $-/$ \\
Stage III & $4 \%-57 \%$ & $1 \%-73 \%$ \\
Stage IV & $8 \%-29 \%$ & $8 \%-09 \%$ \\
Stage V & $2 \%-14 \%$ & $2 \%-18 \%$ \\
\hline
\end{tabular}

$\mathrm{SP}=$ soccer practitioners; $\mathrm{NA}=$ non-athletes .

Table 4. Correlation between of Pubic Hair Growth with other physical characteristics and performance.

\begin{tabular}{ccc}
\hline & Pubic hair growth & $\mathrm{p}$ \\
\hline Age (years) & 0.187 & 0.058 \\
Body mass $(\mathrm{kg})$ & -0.166 & 0.085 \\
Stature $(\mathrm{m})$ & -0.161 & 0.153 \\
BMI $\left(\mathrm{kg} / \mathrm{m}^{2}\right)$ & 0.104 & 0.072 \\
$\%$ fat & 0.046 & 0.096 \\
Test $20 \mathrm{~m}(\mathrm{~m})$ & -0.003 & 0.051 \\
Square test & 0.013 & 0.081 \\
\hline
\end{tabular}

Body composition is important for sports performance, affecting the mobility of the athlete. In this study, body composition did not differ between groups, although stature did differ $(p=0.01)$. Our data corroborate some studies $[1,10]$ where there were no differences in body composition between SP and NA. Changes in body composition are dependent on the intensity and volume of training [17], so the load of training in the group of soccer players in the current study was apparently not effective in causing changes in mass. Nutritional intake may have counteracted any effects of training on body composition. There were differences between past studies 
and the current study, such as the mode of body fat assessment, but the results of these studies show that soccer practice does not necessarily promote differences in body composition in this age group of soccer players as compared to non-athletes.

The regular practice of sport can bring changes in physical attributes to its practitioners. Among the various physical abilities required in a game of soccer, agility and speed are important for development in this game [9]. In this present study comparing neuromuscular capacities (speed and agility) in soccer players and non-athletes, the SP performed better in both capacities; however, there was a significant difference between the groups only for agility $(p=0.017)$. The soccer practice may have influenced a better performance of soccer players in a sportspecific characteristic such as agility. Cyrino et al. [17] submitted youth to 24 weeks of soccer training and compared the effects of training to young people without systematic physical exercise and found differences in strength/muscle power and agility. This result is likely due to systematic soccer practice, leading practitioners to adapt to the specific sport. Neto et al., [1] observed differences in agility, speed and coordination between practitioners and non-athletes age 10 and 11 years. Seabra et al. [6] evaluated the agility, speed, lower limb strength, aerobic endurance and specific skills. Among the variables analyzed in that study, the soccer players performed better on all tests other than lower limb strength and aerobic endurance. As in our current study, soccer players performed better on the speed test $(p=0.001)$. These results show that soccer training leads to an improvement in physical capacity, particularly with respect to agility, in its practitioners.

Regarding the level of maturity, there was no significant difference between SP and NA. This result likely occurred due to the age limit of the study. Different from that found in our study, some authors argue that perhaps practitioners of systematized training tend to have higher levels of maturation than non-athletes $[8,18,19]$.

We attempted to analyze the influence of maturation on exercise performance. There was no significant difference in neuromuscular performance among individuals at different levels of maturation. The level of maturation in our study may have influenced the neuromuscular capacity, but due to low sample size this difference may not have been detected. However, the peak of agility development takes place two years before the peak speed of development that occurs between 14 and 16 years for boys [20]. The lack of association between agility and maturation may be due to our age group, because the peak speed development has already occurred at $14-16$ years, with improvements being slower over subsequent years.

Our research is in agreement with the study of
Mendez-Villanueva et al. [21] where the authors found that maturation may not be related to speed. Our work corroborates the findings of Ré et al. [11], where no significant differences were found between young people with advanced maturation and young people of lesser maturation when physical capacities were analyzed. Maturation can influence performance in some physical abilities and not others [6-8,21-23].

Maturation is the advancement to the state of the mature individual. During adolescence, individuals in a given phase of development can be in the same chronological age but in different biological ages [24]. Maturation can influence the performance of athletes in different maturational stages. When individuals with distant maturational stages are compared, the difference in the analyzed variable is large [19].

The present study had some limitations such as selfevaluation of maturation level that could have been done by a doctor or by using analysis of bone maturation. Analysis of neuromuscular variables could have been performed using devices with photocells. The neuromuscular tests performed were adapted from the literature and are not specific to soccer because there is no consensus in the literature about which tests are best for soccer

\section{CONCLUSION}

It was concluded that individuals who practiced soccer had better results for the agility test than non-athletes, even with no difference between the degree of maturation and speed test. There was a low correlation between level of maturity and agility or speed.

\section{REFERENCES}

[1] Neto, O.B., Barbieri, F.A., Barbieri, R.A. and Gobbi, L.T.B. (2009) Performance of agility, speed and coordination of boys practicing and not playing football. Fitness \& Performance Journal, 8, 110-114.

[2] Bangsbo, J., Mohr, M. and Krustrup, P. (2006) Physical and metabolic demands of training and match play in the elite football player. Journal of Sports Sciences, 24, 665674. doi:10.1080/02640410500482529

[3] Cometti, G., Maffiuletti, N.A., Pousson, M., Chatard, J.C. and Maffulli, N. (2001) Isokinetic strength and anaerobic power of elite, sub-elite and amateur French soccer players. International Journal of Sports Medicine, 22, 45-51. doi:10.1055/s-2001-11331

[4] Hoff, J. (2005) Training and testing physical capacities for elite soccer players. Journal of Sports Science, 23, 573-582. doi:10.1080/02640410400021252

[5] Stolen, T., Chamari, K., Castagna, C. and Wisloff, U. (2005) Physiology of soccer: An update. Sports Medicine, 35, 501-536.

[6] Seabra, A., Maia, J.A. and Garganta, R. (2001) Growth, 
maturation, physical fitness, explosive power and specific motor skills. Study on young players and not male soccer players from 12 to 16 years old. Revista Portuguesa de Ciências do Desporto, 1, 22-35.

[7] Nedeljokovic, A., Mirkov, D.M., Kukolj, M., Ugarkovic, D. and Jaric, S. (2007) Effect of maturation on the relationship between physical performance and body size. Journal of Strength \& Conditioning Research, 21, 245250. doi:10.1519/00124278-200702000-00044

[8] Malina, R.M. (2000) Height, mass and skeletal maturity of elite Portuguese soccer players aged 11 - 16 years. Journal of Sports Sciences, 18, 685-693. doi:10.1080/02640410050120069

[9] Rebelo, A.N. and Oliveira, J. (2006) Relationship between speed, agility and muscle power of professional soccer players. Revista Portuguesa de Ciências do Desporto, 6, 342-348.

[10] Mortatti, A.L. and Arruda, M. (2007) Analyze the effects of training and sexual maturation on the somatotype of young footballers. Brazilian Journal of Kinanthropometry and Human Performance, 9, 84-91.

[11] Ré, A., Bojikian, L.P., Teixeira, C.P. and Böhme, M.T.S. (2005) Relationship between growth, motor performance, chronological age and biological maturation in young male. Revista Brasileira de Educação Física e Esporte, 19, 153-162.

[12] Mascarenhas, L., Neto, A., Bozza, R., Cézar, C. and Campos, W. (2006) Behavior of maximum oxygen consumption and body composition during the maturation process in male adolescents participating in soccer training. Brazilian Journal of Science and Movement, 14, 49-56.

[13] Lohman, T.G. (1986) Applicability of body composition techniques and constants for children and youths. Exercise and Sport Sciences, 14, 325-357.

[14] Tanner, J.M. (1962) Growth at adolescence. 2nd Edition, Blackwell Scientific Publications, Oxford.

[15] Sacchetti, R., Ceciliane, A., Garulli, A., Masoti, A., Polleti, G., Beltrami, P. and Leoni, E. (2012) Physical fitness of primary school children in relation to overweight prevalence and physical activity habits. Journal of Sports
Sciences, 30, 633-640. doi:10.1080/02640414.2012.661070

[16] Levandoski, G., Cieslak, F., Santos, T.K., Carvalho, F.K., Rocha A. and Ogg, F. (2009) Somatotype profile, antropometric variables, physical aptitude and motor behavior of juvenile athletes of female volleyball time from Ponta Grossa-PR. Fitness \& Performance Journal, 8, 27-31.

[17] Cyrino, E.S., Altimari, L.R., Okano, A.H. and Coelho, C.F. (2002) Effects of soccer training on body composition and motor performance of young athletes. Brazilian Journal of Science and Movement, 10, 41-46.

[18] Peeters, M.W., Thomis, M.A., Beunen, G.P. and Malina, R.M. (2009) Genetics and sports: An overview of the pre-molecular biology era. Medicine and Sport Science, 54, 28-42. doi:10.1159/000235695

[19] Philippaerts, R.M., Vaeyens, R., Janssens, M., Renterghem, B.V. and Malina, R.M. (2006) The relationship between peak height velocity and physical performance in youth soccer players. Journal of Sports Sciences, 24, 221-230. doi:10.1080/02640410500189371

[20] Bar-Or, O. (1995) The young athlete: Some physiological considerations. Journal of Sports Sciences, 13, 31-33. doi:10.1080/02640419508732274

[21] Mendez-Villanueva, A., Buchheit, M., Kuitnunen, S., Poon, T.K., Simpson, B. and Peltola, E. (2010) Is the relationship between sprinting and maximal aerobic speeds in young soccer players affected by maturation? Pediatric Exercise Science, 22, 497-510.

[22] Malina, R.M., Ribeiro, B., Aroso, J. and Cumming, S.P. (2007) Charecteristics of youth soccer players $13-15$ years classified by skill level. British Journal of Sports Medicine, 41, 290-295. doi:10.1136/bjsm.2006.031294

[23] Cunha, G., Lorenzi, T., Sapata, K., Lopes, A.L., Gaya, A.C. and Oliveira, A. (2011) Effect of biological maturation on maximal oxygen uptake and ventilatory thresholds in soccer players: An allometric approach. Journal of Sports Sciences, 13:1-11.

[24] Baxter-Jones, A., Eisenmann, J.C. and Shera, L.B. (2005) Controlling for maturation in Pediatric Exercise Science. Pediatric Exercise Science, 17, 18-30. 